\title{
A Comparative Study between Vibration and Acoustic Signals in HTC Cooling Pump and Chilling Pump
}

\author{
S. Devi, Dr. L. Siva Kumar, N.R.Shanker and K.Prabakaran,
}

\begin{abstract}
The aim of this project is to investigate how the vibration signals and the acoustic signals can be used for state monitoring of the operating machines. The Fast Fourier Transform method is used to analyze the characteristics of the machine, based upon which the machinery problems during operation can be diagnosed precisely. The Fast Fourier Transform of the vibration signals and the acoustic signals are computed independently and their recital in the state monitoring of the health condition of operating machines is compared. On time state monitoring in the running condition of the machine is performed, which eliminates the need for a separate day for maintenance when the machines are shut down for monitoring the machine health condition. Hence a reliable process for the state monitoring of the machine health is put forward.
\end{abstract}

Index items-FFT, acoustic signals, vibration, Machines

\section{INTRODUCTION}

In today's competitive Industrial environment, it is very essential to achieve maximum availability of plant and machines. The Industrial equipments are subjected to regress operating conditions and therefore the possibilities of break down from various inaccuracies and problems are quite significant. Therefore, a dynamic predictive maintenance based on machinery problem diagnostics is a must in ensuring trouble free operation. Machinery vibrations are manifestation of the health condition of operating machines. Hence the accurate measurement and correct interpretation of vibrations can help in precisely diagnosing machinery problems during operation. If the vibration amplitudes are high, the health of the machine is not good. Similarly the noise produced by the machines during the operation is also the indication of condition of the machine. Therefore amplitudes of these signals can also be used for the condition monitoring. The acoustic diagnosis of machine state is as efficient as vibration monitoring and cost effective. The most common defects which are associated with plants are listed below:

- Unbalance

- Misalignment

- $\quad$ Bend Shaft

- Mechanical Looseness
- $\quad$ Coupling Defects

- $\quad$ Loose Foundation Bolts

- Cracks in Foundation

- Cracks in Structure

- $\quad$ Piping Forces

- Aero Dynamic Forces

- Resonance Condition

- Defects in Bearings, Gear boxes, Belt driven system

- $\quad$ Electrical Defects

It could be seen that all these defects in different machines can be grouped into 5 categories.

- Unbalance of one or more parts

- Misalignment of system

- Out of tolerance

- Reaction to some external forces

- Unbalanced magnetic forces in drive motors/generators.

In present monitoring system, the defects are diagnosed by color monitoring, smell monitoring, thermography, oil analysis etc., these methods are inefficient and expensive and also the expertise technicians are needed to perform the monitoring. Hence the vibration and acoustic method to do on-machine monitoring system is proposed. The lubricant analysis and vibration measurements are also used still now in the industries. These methods concentrates on the elements of machines such as bearings, gears and pumps but it will not state the conditions for other items on the machine tool that can cause halts $[1,2]$. All the conditions monitoring methods for machines include acoustics and technical diagnostics needs the use of analyzers in real time which is costlier $[3,4,5]$.The analysis test is used in conjunction with Fourier analysis to effectively separate closely spaced harmonic lines [6]

Each diverse bearing has unique characteristic revolving defect frequency which depends on the kinematics concern, 
this frequency can be intended knowing the geometry of the bearing and its revolving speed, Usually these frequency lie in the low-frequency range (less than $500 \mathrm{~Hz}$ ) [7, 8].The existence of a fault in industrial utensils will be accompanied by a noticeable increase or modification of vibratory signal $[9$, 10]

\section{Description Of Vibration Monitoring System}

The state monitoring system using vibration of the machine consists of four elements. The machines are calibrated using vibration sensor for data acquisition, microlog as the interface unit and the computer for the signal processing.

This signal processing is done with the help of software's such as auto signal and prism 4 for windows, mat lab etc.,

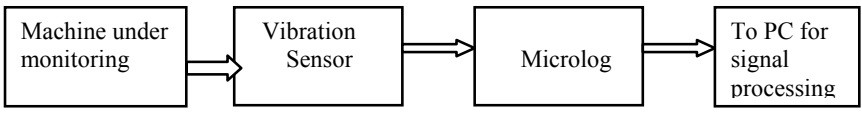

Figure 1.Block diagram of vibration acquisition

\section{VIBRATION SENSOR DETAILS}

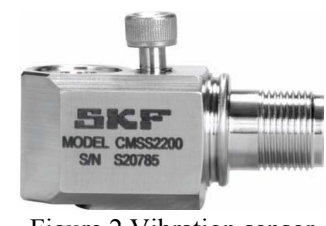

Figure 2.Vibration sensor

- $\quad$ Sensitivity: $100 \mathrm{mV} / \mathrm{g}$

- Sensitivity Precision: $\pm 10 \%$ at $+77^{\circ} \mathrm{F}\left(+25^{\circ} \mathrm{C}\right)$

- Acceleration Range: 80 g peak

- Amplitude Linearity: 1\%

- Frequency Range: $\pm 10 \% ; 1.0 \mathrm{~Hz}$ to $5,000 \mathrm{~Hz} \pm 3$ $\mathrm{dB} ; 0.7 \mathrm{~Hz}$ to $10,000 \mathrm{~Hz}$

- $\quad$ Resonance Frequency: Mounted, minimum $22 \mathrm{kHz}$

- Transverse Sensitivity: $\leq 5 \%$ of axial

- Power Requirements:

- Voltage Source: +18 Vdc to $+30 \mathrm{Vdc}$

Constant Current Diode: 2 to $10 \mathrm{~mA} \mathrm{dc}$, recommended 4 $\mathrm{mA}$

- $\quad$ Electrical Noise: $2.0 \mathrm{~Hz} ; 20 \mu \mathrm{g} / \sqrt{ } \mathrm{Hz}$

- $\quad$ Output Impedance: $<100$ Ohms

- Voltage Bias: 12 Vdc

- Grounding: Case isolated, internal shielding

\section{Micolog SpecificAtion}

- Very big screen that suitable for field service and analysis
- Complete with vibration analysis function such as Run up/Coast down, Bump Test, Frequency Analysis Module, Cyclic Analysis, Motor Current Analysis

- $\quad$ Suitable for field in-depth analysis

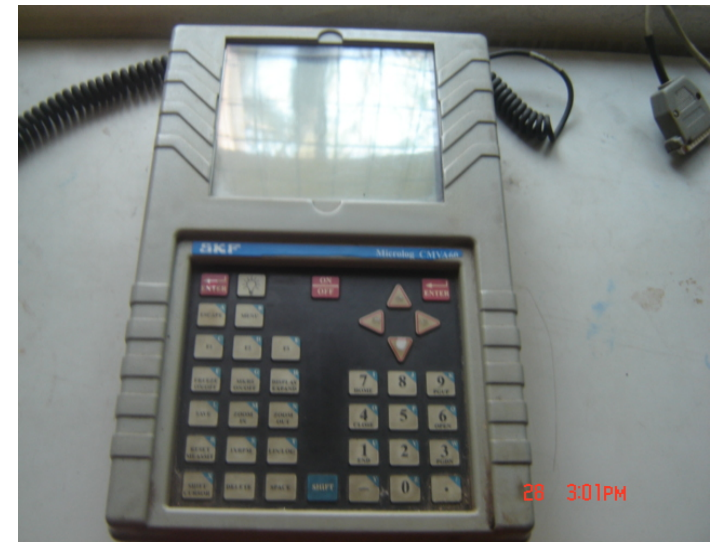

Figure 3. Microlog Instrument

\section{Methodology}

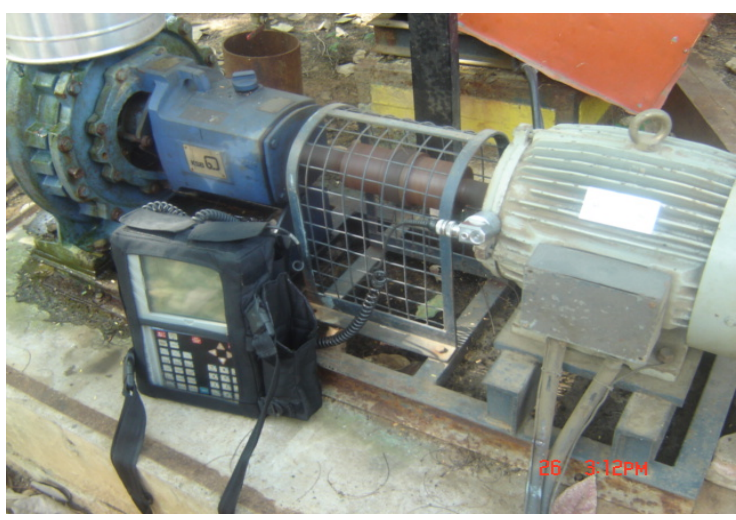

Figure 4.Vibration Senor Mounting

Initially the sensor is mounted on the machine firmly on the running state. The vibration signals are thus captured and given to the signal processing software through the microlog unit. The vibration signals are taken in three axis i.e. Horizontal, vertical and axial directions. The software is used to compute the Fast Fourier Transform (FFT) of the signal. FFT is the parameter used for condition indication. Higher the value of FFT, higher is the vibrations which in turn indicate the fault in the machine. Thus the state of the machine is determined.

\section{DESCRIPTION OF ON-MACHINE MONITORING USING ACOUSTIC SIGNALS}

The acoustic and vibration signals can be closely allied together. The main advantage of acoustic signal is that they are airborne. Hence the microphone is enough to capture the signals whereas in vibration monitoring, the sensor has to be mounted on the machine under interest hence error in the monitoring may be produced due to misalignment of the sensor. As sound signals are airborne, the portable system can be realized. The system employing acoustic signals for monitoring consist of four units as shown. 


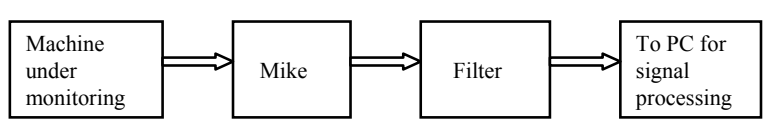

Figure 5.Block diagram of Acoustic signal Acquisition

The machine to be monitored, a microphone to capture the sound signals, a filter and the PC for signal analysis. The only disadvantage of this technique is that while capturing the sound signals there is a chance for the other signals to interrupt. To minimize this problem, the filter is used. The signal processing software to compute FFT of the signal used in this method is auto signal software. The state of the machine is determined with the value of FFT as done in the vibration monitoring.

\section{ACOUSTIC SENSOR}

Impedance:32ohms Driver Unit: $9.7 \mathrm{~mm}$ driver unit FrequencyResponse:30Hz $16,000 \mathrm{~Hz}$

MicrophoneSensitivity:-58dB+/-3Db OutputPower: $80 \mathrm{~mW}$ Input/Output Plugs: $3.5 \mathrm{~mm}$ stereo plugs

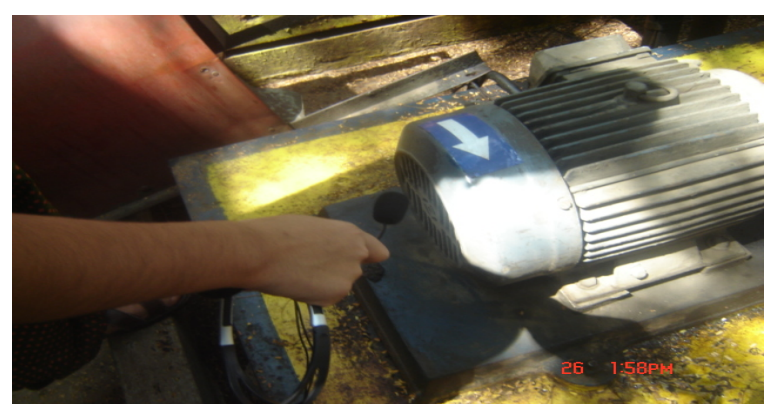

Figure 6.Acoustic Signal Acquisition

The mike pin connected to the PC is placed $1-2 \mathrm{~cm}$ away from the machine so that it is not in direct contact with the machine. The mike is covered by the EMR filter to prevent the noise signals from the environment being capture. Hence the noise from the machine is captured by the mike pin through $\mathrm{d}$ sound recorder and then is given to the PC with some suitable signal analysis software such as AUTOSIGNAL and MATLAB. FFT of the signals is plotted and using that, the machine state is predicted.

\section{RESULTS AND DiCUSSIONS}

For vibration monitoring, the vibration sensor, $\mathrm{PC}$, microlog, software for Signal processing like auto signal and Prism4 for windows .For acoustic signal monitoring, The microphone, PC, Software for signal processing like auto signal, mat lab etc., the filter.
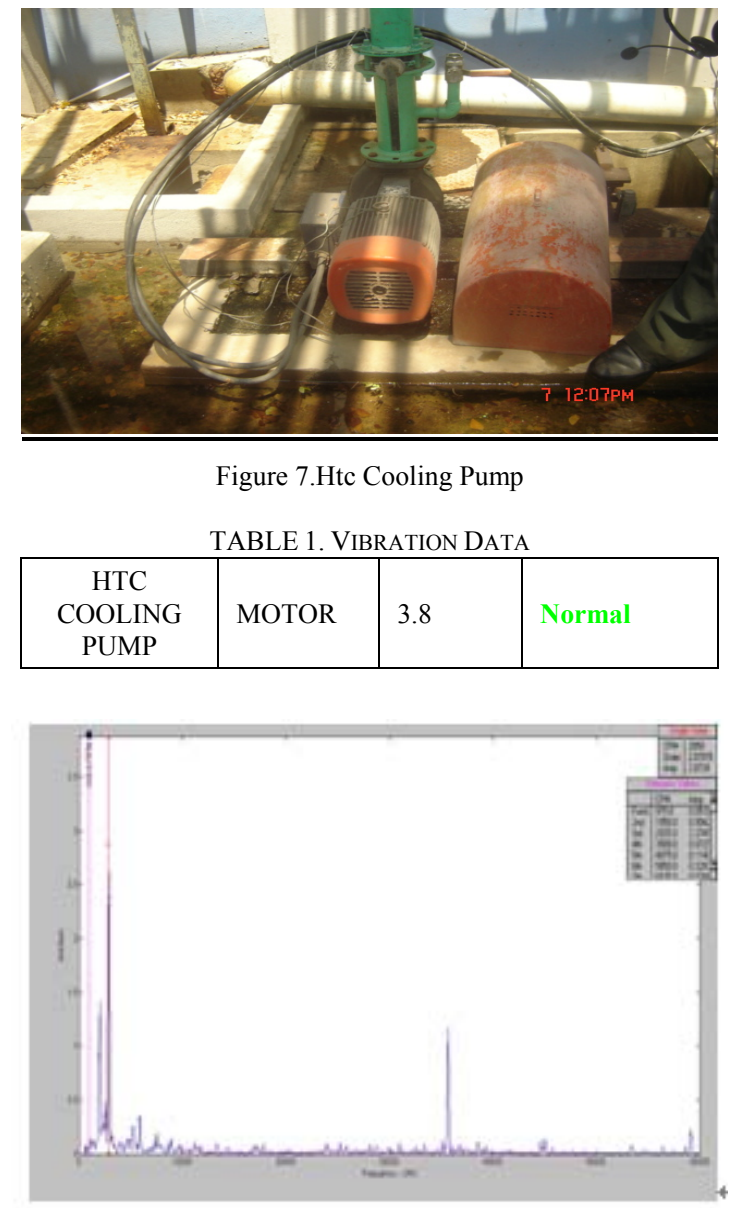

Figure 7. FFT value of the vibration signal $=3.8 \quad$ Machine condition NORMAL

\begin{tabular}{|c|l|l|l|}
\hline \multicolumn{4}{|c}{ TABLE 2. ACOUSTIC DATA } \\
\hline $\begin{array}{c}\text { HTC } \\
\text { COOLING } \\
\text { PUMP }\end{array}$ & MOTOR & 0.0687 & Normal \\
\hline
\end{tabular}

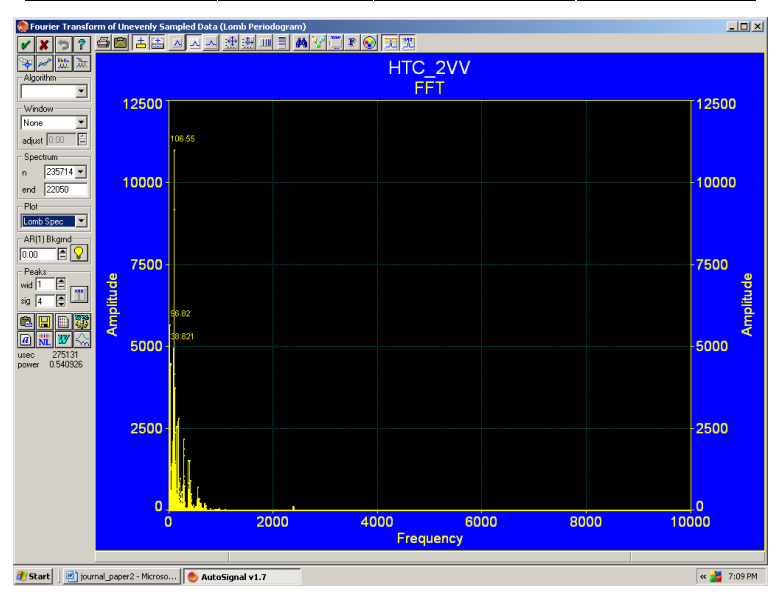

Figure 8 FFT value of the vibration signal $=0.0687$ Machine condition NORMAL

Observations and Inference of the equipment is indicating a Normal condition with maximum vibration amplitudes of $3.8 \mathrm{~mm} / \mathrm{s}$ at motor with the dominance of rotational speed. Minor looseness is indicated at motor base.

Action Plan to monitor the deteriorations. 


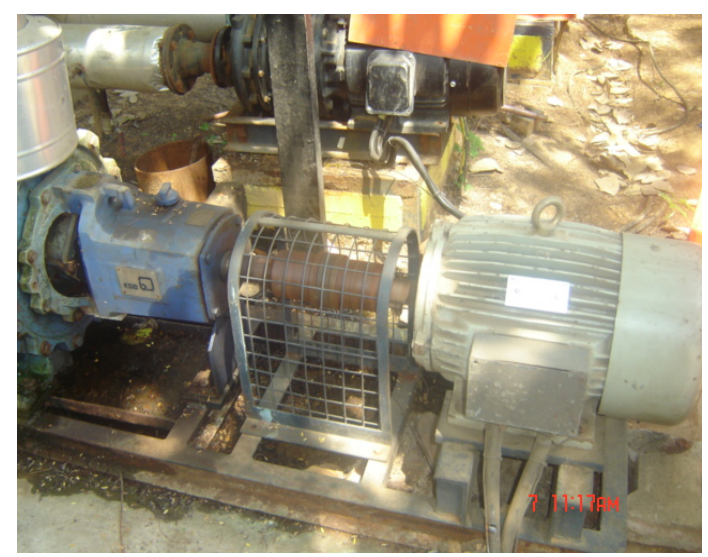

Figure 9 Chilling Water Pump

TABLE 3.VIBRATION DATA

\begin{tabular}{|c|c|c|c|}
\hline \multirow{2}{*}{ CHILLING WATER PUMP 5 } & MOTOR & $\begin{array}{c}23 . \\
5\end{array}$ & Alarm \\
\cline { 2 - 4 } & PUMP & 8.3 & Alert \\
\hline
\end{tabular}

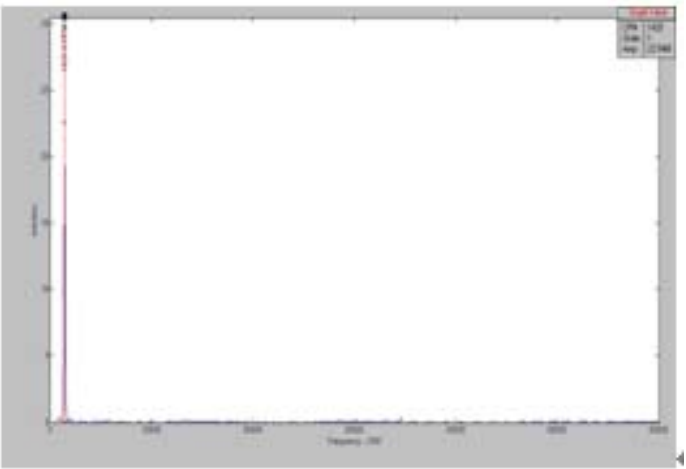

Figure 9.FFT value of the vibration Motor signal $=23.5$, Machine condition - ALARM

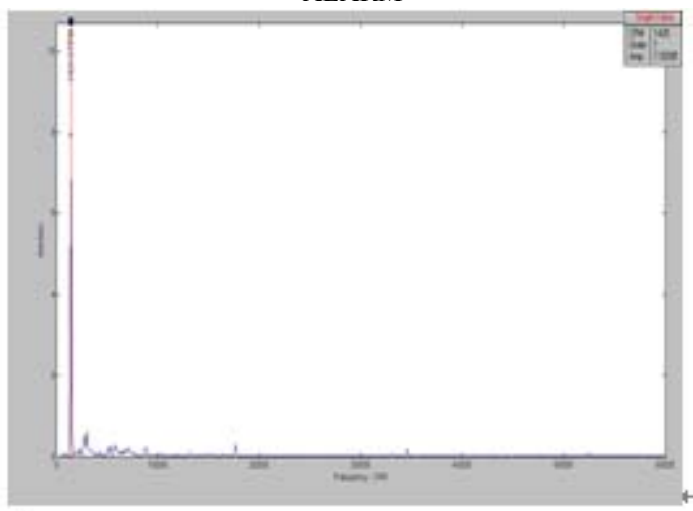

Figure 10.FFT value of the vibration pump signal $=8.3$ Machine condition - ALERT

\begin{tabular}{|c|c|c|c|}
\hline \multirow{2}{*}{$\begin{array}{c}\text { CHILLING } \\
\text { WATER } \\
\text { PUMP }\end{array}$} & MOTOR & 0.337 & Alarm \\
\hline & PUMP & 0.138 & Alert \\
\hline
\end{tabular}

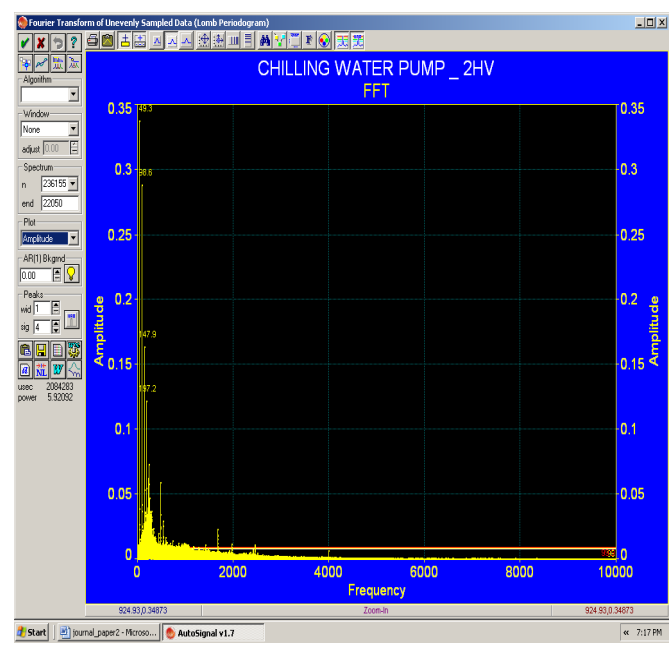

Figure 11.FFT value of the motor vibration signal $=0.337$ Machine condition - ALARM

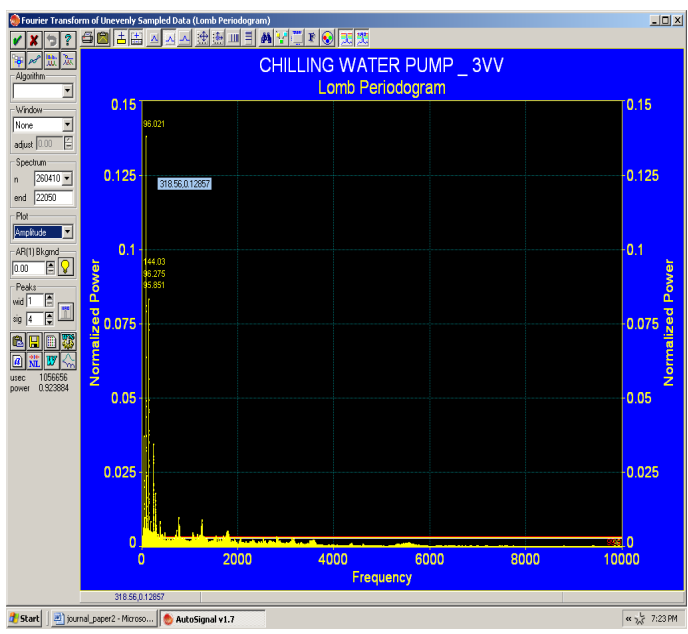

Figure 12.FFT value of the Pump vibration signal $=0.138$ Machine condition - ALERT

Observations and Inference the equipment is indicating an Alarm condition with maximum vibration amplitudes of 23.5 $\mathrm{mm} / \mathrm{s}$ at motor with the dominance of rotational speed $\&$ minor harmonics. Inadequate area contact \& significant looseness (missing foundation bolts at motor free end) between motor/pump base $\&$ its foundation. Misalignment is indicated between motor $\&$ pump.

Action Plan to ensure at least $80 \%$ area contact $\&$ uniform tightness between system (especially motor) base $\&$ its foundation. Achieve precision alignment between motor \& pump within $+/-0.05 \mathrm{~mm}$ both radially \& axially.

\section{CONCLUSION}

Through the analysis of number of samples obtained from the machines, the standard FFT values for the vibration and acoustic signals to determine the health condition of the machine is found as follows. The condition of the machines is categorized into three states. They are Normal, alert and alarm. 
TABLE 5.FOR VIBRATION SIGNAL

\begin{tabular}{|l|l|}
\hline FFT RANGE & MACHINE STATE \\
\hline Less than 6.3 & Normal \\
\hline 6.3 to 15.8 & Alert \\
\hline Greater than 15.8 & Alarm \\
\hline
\end{tabular}

TABLE 6.FOR ACOUSTIC SIGNAL

\begin{tabular}{|l|l|}
\hline FFT RANGE & MACHINE STATE \\
\hline Less Than 0.11 & Normal \\
\hline 0.11 to 0.215 & Alert \\
\hline Greater Than 0.215 & Alarm \\
\hline
\end{tabular}

The state monitoring of the machines can be done effectively using the vibrations of the machine as well as the sound signals. Even though both the acoustic and vibration signals can be utilized for the condition monitoring, it is proposed that the acoustic signals may be employed by the industries for on-machine monitoring for the predictive maintenance as the acoustic analysis cost less than the vibration analysis.

\section{REFERENCE}

[1] Katter, J. G. \& Jay, F. T. 1996. Bearing Condition Monitoring for Preventative Maintenance in a Production Environment. Tribology Transactions, Vol. 39, 4, pp. 936-942

[2] Thorpe, P. J. \& Martin K. F. 1991. Milling machine bearing monitoring. Proc. I. Mech. E. Conf. Eurotech Direct '91, Paper C414/030, pp. 151-157

[3] A. Lucifredi, P Silvestri, "Virtual experimental modal analysis: an application of simulation models to diagnostics". The Fifth International Conference on Condition Monitoring and Machinery Failure Prevention Technologies (CM 2008 / MFPT 2008), Scotland, UK, 2008.

[4] P. Santin, G. Sedmak, "A real-time spectrum analyser with on-line definition of the confidence levels". Astrophysics and Space Science, Vol. 48, No. 1, 1977, 57-63.

[5] R.C.Wu, C.T. Chiang, J.I. Tasi," The real-time optimal spectrum analysis system based on personal computer". Applied Simulation and Modeling (ASM), Greece, 2006.

[6] D. Thompson, Spectrum estimation and harmonic Analysis, Proc. IEEE, V70, pp.1055-1096, 1982.

[7] Tandon N., Yadava G.S. \& Ramakrishna K.M. (2007) A comparison of some condition monitoring Techniques for the detection of defect in induction Motor ball bearings. Mechanical Systems and Signal Processing, 21, 244-256.

[8] Integrated http://www.tpub.com/content/neets/14177/css/14177 94.htm

[9] Al-Ghamda A.M., Mbab D. (2006) A comparative experimental study on the use of acoustic emission and vibration analysis for bearing defect identification and estimation of defect size. Mechanical Systems and Signal Processing, 20(7), 1537-1571.

[10] Carnero M.C. (2005) Selection of diagnostic techniques and instrumentation in a predictive maintenance program. A case study. Decision support systems,38(4), 539-55.

[11] www.mathworks.com

[12] www.ieee.org

[13] www.youtube.com

[14] http://nptel.iitm.ac.in

S. Devi completed his Bachelors degree in Electronics and Communication Engineering (1999) from Periyar Maniammai College of Technology, India and Master's Degree in Communication Systems (2003) form Dr. MGR University, Chennai, India. Currently, she is pursuing her $\mathrm{PhD}$ degree in Anna University, Coimbatore, India. Her areas of interest are signal processing, acoustic engineering and vibration
Dr. L. Siva Kumar completed his B.E degree form Regional engineering college Trichy (1970). Msc (Engg) in Applied Electronics and Servomechanism from PSG college of Technology (1972). Doctoral degree from IIT Karapur (1980)

N.R. Shanker completed his Bachelors degree in Electronics and Communication Engineering (1998) from Madras University, Chennai, India and Master's Degree in Remote Sensing (2003) from Anna University, Chennai, India. Currently, he is pursuing his PhD degree in Anna University, Chennai, India and working as a Lecturer in Aalim Muhammed Salegh College of Engineering, I.A.F., Avadi, and Chennai. He is also a member in IACSIT

K. Prabakaran completed his Bachelors degree in Electrical and Electronics Engineering (1997) from Madras University, Chennai, India and Master's Degree in Energy Engineering (2004) from VIT University, Vellore, India. His area of interest is embedded systems and energy management. 